\title{
Using Conjoint Analysis to Elicit Preferences for Occupational Health Services in Small and Microenterprises
}

\author{
By Mirella Cacace* \\ Ingrid Franz ${ }^{\dagger}$ \\ Dieter Ratz ${ }^{*}$
}

In particular small and medium sized enterprises (SME) benefit from occupational health services as these may help reducing potential costs of accidents or illnesses at work, support staff retention and recruitment, and decrease wage costs. Nevertheless SME and especially microenterprises ( $<10$ persons employed) rarely offer these services to their employees. The innovation incubator's project "Healthy at Work" offers research-based advice to private service units to support SME with the supply of occupational health services the region of Luneburg. This contribution describes the method of eliciting preferences and willingness to pay (WTP) of SME for occupational health services using an Adaptive Choice Based Conjoint Analysis combined with a short WTP questionnaire. The results reveal that a comprehensive service package tailored to the needs of the individual company should be offered on a pay per use basis. The private supplier would benefit from cooperation with a social insurance provider, either health insurance fund or occupational accident insurer. Further, we find that employers are willing to pay for services, WTP decreases with company size, however. It is therefore of particular importance to offer appealing and affordable occupational health services to microenterprises, preferably in cooperation with social insurance providers.

\section{Introduction}

Workforce in Germany is projected to decrease tremendously while average age is increasing (Fuchs et al. 2011). At the same time, illness-related absences from work lead to considerable productivity losses (BAuA 2012). In particular small and medium enterprises (SME) with limited personnel resources and a high demand for skilled workers will have to face these challenges. Against this background, it is of particular importance to keep employees healthy, for example by offering occupational health services, such

\footnotetext{
${ }^{*}$ Visiting Professor, Leuphana University Luneburg, Germany.

${ }^{\dagger}$ Research Fellow, Leuphana University Luneburg, Germany.

${ }^{*}$ Market Researcher, M-Forschung, Hamburg, Germany.
} 
as programs for health promotion and prevention of work related diseases. Occupational health services may help reducing potential costs of accidents or illnesses at work, enhance the general reputation of the company, support staff retention and recruitment and, finally, decrease wage costs (Miller et al. 2002). However, SME and especially microenterprises ( $<10$ persons employed) rarely offer these services to their employees (Harrison et al. 2013). In line with the observations made by Zelfel et al. (2011) our previous studies show, that besides time requirements and financial support - the lack of qualified support structures is a major cause for this deficit (Cacace et al. forthcoming 2015).

The innovation incubator's project "Healthy at Work" supports the creation of private service units offering health education, prevention programs, and occupational rehabilitation in the region of Luneburg. The aim of our research within this project is to support these units in developing services according to the preferences of SMEs. For this purpose we conducted a conjoint analysis (CA), and, as the supplier of services will be a private forprofit provider, we also investigate whether SME are willing to pay for these services. In the following section, the research design and the method for eliciting preferences and willingness to pay (WTP) are explained. Then, we present the results and discuss these against the background of the aim of the "Healthy at Work" project i.e. supporting a private service provider in the supply of occupational health services to SME and microenterprises, in particular.

\section{Method and Research Design}

\section{Pre-studies}

From a quantitative survey amongst $72 \mathrm{SME}$ in the region of Luneburg, which was also part of the "Healthy at Work" project, we learned that SME need professional expertise and support structures from outside the company to offer occupational health services to their employees (Cacace et al. forthcoming 2015). These structures need to respond to the specific requirements of SME. ${ }^{1}$ Accordingly, the research question for the present study was how services could be tailored according to the preference of SME, in particular microenterprises. In order to elicit preferences and WTP for occupational health services in SME and microenterprises, we conducted a CA followed by a WTP interview. Both parts were preceded by qualitative research. In qualitative pre-studies we conducted expert interviews with various actors involved in occupational health, such as accident and health insurers, trade chambers as well as guilds and professional associations. Further, we organized focus group discussions with SME, or - more precisely with the person responsible for the purchasing decision on occupational health services within the SME. In many cases, due to small size of enterprises, this person is identical with the owner of the company. Expert interviews and focus

${ }^{1}$ Based on a much larger study surveying 1441 SME all over Germany Zelfel et al. (2011) come to the same results. 
group discussions were essential for the formulation of attributes and attribute levels in the CA (see below) in order to avoid omitted variable bias (see Clark et al. 2014). Another benefit of qualitative research was to get familiar with the particular vocabulary related to occupational health services the respondents use. Finally, our analysis was preceded by an in-depth market screening of existing supply structures for occupational health services.

\section{Conjoint Analysis}

The CA method is based on the seminal work of Luce and Tukey (1964) describing the essential character of simultaneous conjoint measurement. Today, CA is the preferred method in market research to measure consumer preferences for new products and concepts by assessing partial benefit values to single product characteristics or attributes (Green and Srinivasan 1978). In health economics, it is frequently used to assess consumers' preferences for health care service delivery and a range of other health applications. ${ }^{1} \mathrm{CA}$ is a decompositional method, based on the assumption that a product or service can be described by its attributes. The value of the product or service depends on the nature and level of these attributes. Within an experimental setting, CA provides answers on the importance of single attributes and on the utility, attribute combinations provide to respondents. It "show(s) how people are willing to trade between characteristics" (Ryan and Farrar 2000:1530), which is useful when deciding on the optimal way to provide a good or service within limited resources. During a conjoint interview, through several iterations, respondents are shown different product profiles and are asked to choose the favored alternative. By the disaggregated evaluation of the utilities respondents assign to single attribute levels, CA estimates the overall preference or utility associated with each level of each attribute. This separation is called attribute specific part-worth function. From part-worth function overall utility scores and the relative importance of single attributes can be computed (Rao 2014). This way CA reveals the underlying preference function.

\section{Research Design}

For our survey we recruited $75 \mathrm{SME}$ by telephone in urban and rural areas in the region of Luneburg. Response rate was $100 \%$ which means that all recruited SME responded our survey consisting of a CA part and a WTP section. SME operate in the following sectors: childcare, hairdressing, automotive and metal-processing industry, dentistry, construction and agriculture as well as cleaning, long-term care, hotel/gastronomy and food industry. 62 persons were employed in the largest SME participating in the study, only two in the smallest. About $49 \%$ were microenterprises with less than ten persons employed.

The questionnaire was designed as a computer-aided survey using the Sawtooth Software package SSI Web 8.3.2. For quality purposes we opted for a self-administered questionnaire combined with supervision by interviewers

${ }^{1}$ See e.g. reviews by Clark et al. (2014), De Bekker-Grob et al. (2012), Ryan and Farrar (2000), or Ratcliffe (2000). 
(Bourque and Fiedler 2003; Ryan/Gerard 2003). Interviewers' role was restricted to explanation and assistance in the case respondents had questions. Field time was between January 13th and March 31st, 2014. Duration of interviews was 37.3 minutes on average.

Amongst multiple CA approaches available in the Sawtooth package, we opted for the Adaptive Choice-based Conjoint Analysis (ACBC) combining the advantage of the widely employed choice-based approaches with an adaptive element. ACBC is recommended based on the decisions we made regarding the research design, such as sample size, complexity of the attribute list, length of the survey, and the mode of interviewing (Orme 2013) The ACBC interview is interactive, customizing the questionnaire to respondent's previous choices, which makes the tasks more engaging compared to non-adaptive versions of the choice-based approach (Sawtooth Software 2014). This factor is an essential contribution to the quality of the estimation results for utilities, allowing for a better prediction of real-world preferences (Cunningham et al. 2010). Moreover, ACBC incorporates elements of non-compensatory decision making, which means that there are "must-haves" in attribute levels, the respondent strongly prefers and is not willing to trade-off. ACBC therefore is capable to model simplified rules of decision, which are likely to occur within complex real-word choice tasks (Johnson 2008).

\section{Attributes and Attribute Levels}

For the construction of attributes and attribute levels we reviewed the transcribed expert interviews and focus groups discussions. Together with the broader picture derived from the market screening, the range of relevant attributes and attribute levels was determined thus setting up the decision framework for the conjoint interviews.

In sum, we identified ten attributes the planned service should be composed of; seven attributes relating to the core service to be tested and another three attributes to additional service offers. The seven attributes relating to the core service are:

1 Content of the occupational health service package (=supplied services)

2 General approach of service delivery (=approach)

3 Cooperation seeking by the private, commercial service provider, e.g. with a health insurance fund (=affiliation)

4 Tailoring of services to specific needs (=customization)

5 Contractual arrangements and payment form (=contract)

6 Certification of the supplier (=certification)

7 Provision of an award to the participating SME (=awarding)

The additional services we tested are:

I 'Navigation function', including assistance in the administration of formalities related to the absence of workers and the search for (co-) funding for occupational health services (=navigation function yes/no) 
II Needs assessment tailored to the risks and requirements of the specific SME (=needs assessment yes/no)

III Planning and conceptualization of occupational integration management ${ }^{1}$ (=occupational integration management yes/no)

Table 1 (see next page) lists the attributes together with the attribute levels, which we set up and refined after pre-testing the questionnaire. The attribute list was presented to all respondents in the fixed order presented above. We therefore cannot exclude sequence effects, meaning that respondents give relatively high attention to the attributes on top, and less to those at the bottom of the list (Chrzan 1994). However, we accepted this (potential) effect as the sequence of attributes is part of our research design with core services at the beginning and additional services towards the end of the attribute list. We therefore refrained from attribute rotation.

In line with the recommendations for good practice in the application of conjoint analysis in health care (Bridges et al. 2011), also hypothetical attribute levels are included in the chosen levels in order to encompass the range salient to subjects. (Currently) unavailable levels - at least according to our knowledge based on the market screening - include for example the awarding attribute $^{2}$, insurance-based contracting as well as the navigation function.

An attribute frequently included in CA is price in order to elicit WTP for the planned product or service (Ratcliffe 2000). From qualitative research, however, we learned that participants revealed no or very low willingness to pay for occupational health services in general. Two dominant motives became obvious from the focus group discussions. First, the benefits of occupational health services are - as of yet - rather unclear to SME, which is in line with the results Zelfel et al. (2011) derived in their larger study. Second, due to restricted financial resources, SMEs tend to shift responsibility for paying for occupational health services to other actors, in particular to employers' liability insurance association. Against this background, we found advisable to separate WTP from ACBC in order to avoid dominance of WTP criteria over all other attributes of the planned service. At the same time, we used the favourable situation directly after the ACBC to ask for WTP for the ideal service package, the respondent has just composed during the interview. This procedure had the crucial advantage that respondents - through the interview procedure - have learned about the service offer and its potential benefits. However, results therefore have to be interpreted with caution as they represent WTP related to the individually optimal service offer.

\footnotetext{
${ }^{1}$ According to German social legislation, occupational integration management (=Betriebliches Eingliederungsmanagement, BEM) is an offer the employer is obliged to make to workers in the event of absence due to sickness of more than 30 days per year. In particular SME are challenged by this obligation (Zelfel et al. 2011).

${ }^{2}$ Both the „Healthy Workplace” as well as the TÜV award are fictitious.
} 
Table 1. Overview of Attributes and Attribute Levels

\begin{tabular}{|c|c|}
\hline Attribute & Attribute Level \\
\hline $\begin{array}{l}\text { Supplied } \\
\text { Service }\end{array}$ & $\begin{array}{l}\text { Prevention of physical illness (e.g. skin disease, back pain) } \\
\text { Prevention of mental illness (e.g. stress reduction) } \\
\text { Team building } \\
\text { Combination of physical and mental illness prevention } \\
\text { Combination of physical illness prevention and team building } \\
\text { Combination of mental illness prevention and team building } \\
\text { Combination of physical/mental illness prevention and team building }\end{array}$ \\
\hline Approach & $\begin{array}{l}\text { In-house coaching/training of employees } \\
\text { Coaching/training of employees outside the company, e.g. in training } \\
\text { centers } \\
\text { In-house coaching of the manager(s) (capacity building) } \\
\text { Cross-company coaching/training to allow for exchange of ideas }\end{array}$ \\
\hline Affiliation & $\begin{array}{l}\text { Chamber of Trade / Chamber of Industry and Commerce } \\
\text { Health Insurance Fund } \\
\text { Guild/professional associations } \\
\text { Occupational Accident Insurance } \\
\text { Private supplier (no affiliation) }\end{array}$ \\
\hline Customization & $\begin{array}{l}\text { Service customized to the needs of individual employees } \\
\text { Service customized to the needs of the individual company } \\
\text { Branch-specific tailoring of services } \\
\text { No customization of services }\end{array}$ \\
\hline Contract & $\begin{array}{l}\text { Pay per use } \\
\text { Middle- or long-term service contract withInsurance coverage of } \\
\text { services }\end{array}$ \\
\hline $\begin{array}{l}\text { Supplier } \\
\text { Certification }\end{array}$ & Yes / No \\
\hline Awarding & $\begin{array}{l}\text { No award provided to the company } \\
\text { Company receives the „Healthy Workplace“ award } \\
\text { Company receives TÜV award }\end{array}$ \\
\hline add. Service 1 & Navigation function: yes/no \\
\hline add. Service 2 & Needs assessment: yes/no \\
\hline add. Service 3 & Occupational integration management: yes/no \\
\hline
\end{tabular}

ACBC interview was immediately followed by a short WTP interview, asking the following core questions:

(1)If the 'ideal' service package - i.e. the one you prefer most would be available at the market, would you in general be willing to pay for it? (answer options "yes"/"no")

(2)If yes, how much would you be willing to pay for it? (answer in monetary categories: < 5 Euro, 5-10 Euro, 10-15 Euro, > 15 Euro)

Question 2 presented the WTP question according to the payment card technique (Ryan et al. 2004), where respondents are presented a range of bids and asked to indicate the range that represents the most they would be willing 
to pay. In accordance with the information obtained during focus group discussions, the suggested monetary categories started with 5 Euro or less up to under 15 Euro per employee and month. We accept the ambiguity resulting from the use of ranges (Bridges et al. 2011:406) as the payment card technique is the more realistic alternative compared to others (Ryan et al. 2004).

\section{Questionnaire and Interview Procedure}

Our survey started with some socio-demographic questions, followed by the ACBC part and the WTP section. ACBC typically includes three core sections, which are the "build your own" (BYO) section, the screening section, and the choice tasks. ${ }^{1}$ The aim of the ACBC design is to cope with the complexity of the study regarding attributes and attribute levels on the one hand to and the restrictions in terms of sample size and respondent fatigue on the other. Before starting the BYO section, interviewers were advised to show and explain the attribute list (see Table 1) to the respondents. This was of particular importance since - as described above - hypothetical attribute levels, such as the navigation function e.g. were included in our study. Within the BYO section the respondents were asked to indicate the preferred attribute levels. From this information the program creates a pool of concepts that are relatively concentrated around the respondents preferred attribute levels. As a side effect, the BYO task also serves as a training exercise to further acquaint respondents with the attributes and levels being studied (Orme 2013:4).

In the screening section respondents were shown three different service alternatives at a time and were asked to indicate, which of these services they would consider. This procedure is repeated eight times in our study. It is interrupted by phases questioning respondents if one of the given attribute levels is absolutely unacceptable (five repetitions) or some levels are "must have" attributes (four repetitions). The "must have" and "unacceptable" questions limit and adjust the choice sets in the last section, the choice task section. The following Figure 1 shows the task performed in the screening section.

\footnotetext{
${ }^{1}$ See Sawtooth Software (2014) for a more detailed description of the procedure.
} 
Figure 1. Screening Section

Interviewer: "Here are a few service offers you might like. For each, indicate whether it is a possibility or not. "

\begin{tabular}{|c|c|c|c|}
\hline $\begin{array}{l}\text { Supplied } \\
\text { Service }\end{array}$ & $\begin{array}{l}\text { Physical and mental } \\
\text { illness prevention }\end{array}$ & $\begin{array}{c}\text { Physical illness } \\
\text { prevention }\end{array}$ & Teambuilding \\
\hline Approach & $\begin{array}{l}\text { In-house coaching/ } \\
\text { training of employees }\end{array}$ & $\begin{array}{c}\text { Cross-company } \\
\text { coaching/training }\end{array}$ & $\begin{array}{l}\text { In-house coaching/ } \\
\text { training of employees }\end{array}$ \\
\hline Affiliation & Health Insurance Fund & $\begin{array}{c}\text { Occupational Accident } \\
\text { Insurance }\end{array}$ & $\begin{array}{c}\text { Guild/professional } \\
\text { associations }\end{array}$ \\
\hline Customization & Individual employees & Branch-specific & Individual employees \\
\hline Contract & Pay 1 & er use & Insurance coverage \\
\hline Certification & Supplier certification & $\begin{array}{l}\text { No supplier } \\
\text { certification }\end{array}$ & $\begin{array}{l}\text { No supplier } \\
\text { certification }\end{array}$ \\
\hline Awarding & „Healthy Workplace“ & No award & TÜV-award \\
\hline add. $S$ & Navigat & No navigation function & No navigation function \\
\hline add. Service 2 & Needs assessment & No needs assessment & Needs assessment \\
\hline \multirow[t]{2}{*}{ add. Service 3} & $\begin{array}{c}\text { Occupational } \\
\text { integration management }\end{array}$ & $\begin{array}{c}\text { No occupational } \\
\text { integration management }\end{array}$ & $\begin{array}{c}\text { Occupational } \\
\text { integration management }\end{array}$ \\
\hline & $\begin{array}{c}\square \text { A possibility } \\
\square \text { Won't work for me }\end{array}$ & $\begin{array}{c}\square \text { A possibility } \\
\square \text { Won't work for me }\end{array}$ & $\begin{array}{c}\square \text { A possibility } \\
\square \text { Won't work for me }\end{array}$ \\
\hline
\end{tabular}

In the choice task section respondents are shown three alternative service bundles at a time composed of the chosen product concepts. Figure 2 provides an example for the choice task.

Figure 2. Choice Task

Interviewer: „Among these three options, which would you prefer most? Attributes with identical levels are highlited in grey to make it easier, to focus on differences. “

\begin{tabular}{|c|c|c|c|}
\hline $\begin{array}{c}\text { Supplied } \\
\text { Service }\end{array}$ & $\begin{array}{c}\text { Physical and mental } \\
\text { illness prevention }\end{array}$ & Physical illness prevention & Teambuilding \\
\hline Approach & $\begin{array}{c}\text { In-house coaching/ } \\
\text { training of employees }\end{array}$ & $\begin{array}{c}\text { Cross-company } \\
\text { coaching/training }\end{array}$ & $\begin{array}{c}\text { In-house coaching/ } \\
\text { training of employees }\end{array}$ \\
\hline Customization & $\begin{array}{c}\text { Individual employees } \\
\text { Insurance }\end{array}$ & $\begin{array}{c}\text { Individual employees } \\
\text { Insurance }\end{array}$ & Individual employees \\
\hline Contract & Pay per use & Pay per use & Insurance coverage \\
\hline Certification & Supplier certification & No supplier certification & No supplier certification \\
\hline Awarding & „Healthy Workplace“ & No award & TÜV-award \\
\hline add. Service 1 & Navigation function & Navigation function & Navigation function \\
\hline add. Service 2 & Needs assessment & No needs assessment & Needs assessment \\
\hline add. Service 3 & $\begin{array}{c}\text { Occupational integration } \\
\text { management }\end{array}$ & $\begin{array}{c}\text { No occupational } \\
\text { integration management }\end{array}$ & $\begin{array}{c}\text { Occupational integration } \\
\text { management }\end{array}$ \\
\hline
\end{tabular}


Depending on the answers provided in previous sections a maximum of ten different choice tasks and twenty different product concepts are shown to the respondent. Some service bundles were repeated to improve the estimation of the part-worth utilities.

For several reasons we refuse to include the none-option (i.e. the respondent choses none of the offered alternatives) in our choice section. First, we have no status quo to compare with in our study, which could make the inclusion of the none-option meaningful. Second, including the none-option may discourage some respondents from doing the cognitive work necessary to report the true opinions they do have (Krosnick et al. 2002). According to Krosnick et al. (2002), it is unlikely that the quality of responses is compromised by this omission. Another decision we made relates to the prohibition of levels from occurring with others. Researchers use this option in order to make the suggested profiles as realistic as possible. However, Lancsar and Louviere (2006) strongly advise against this option, which according to Orme (2002) can lead to imprecise utility estimation or even to the complete inability to calculate stable utilities. Against this background, we refrained entirely from using prohibitions, in particular, as the selection of our attribute levels revealed few implausible combinations.

ACBC was analyzed using a multinomial logit model. Part-worth utilities in the choice section were estimated by using ACBC's Hierarchical Bayes program permitting high quality individual-level analysis (Sawtooth Software 2014, cf. also Cunningham et al. 2010). With the ACBC design employed in the study, an optimal compromise was made between the number of stimuli shown to the respondents to produce as many data for consistent estimations and the limited cognitive capacity of the respondents. Based on a test phase with hypothetical data, the design proved to be efficient, reliable, and robust.

\section{Results}

Results from Adaptive Choice-based Conjoint Analysis

The first result ACBC provides is the relative importance of each attribute, computed as an average over all respondents. Figure 3 shows relative attribute importance in percentages. 
Figure 3. Relative Attribute Importance in Percentages

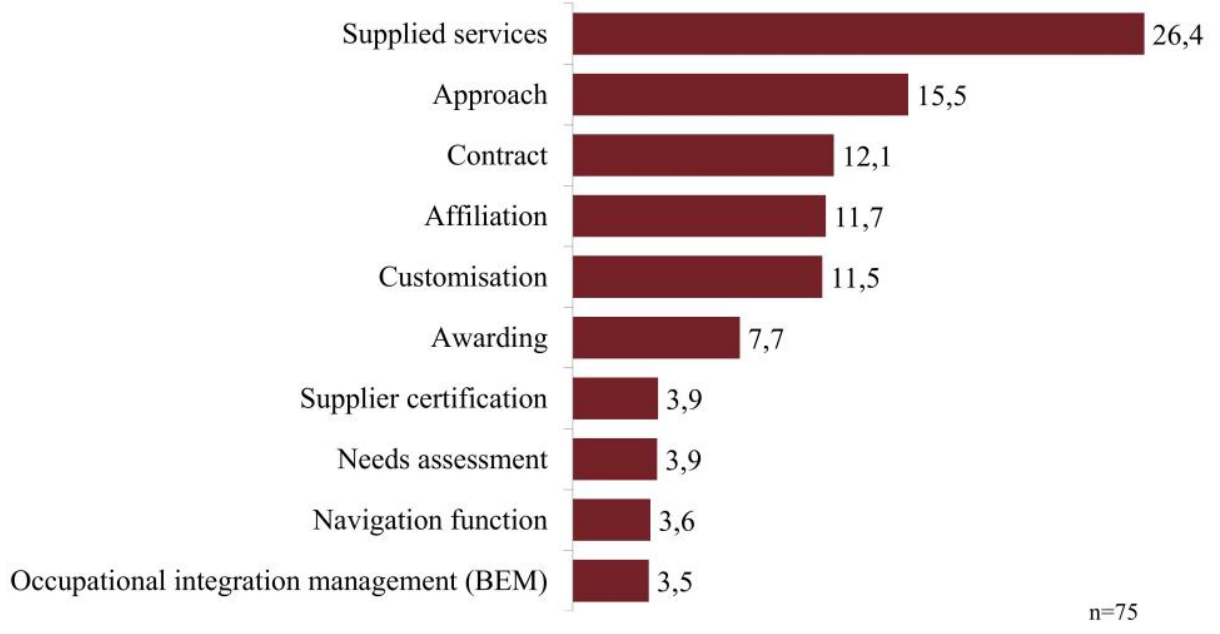

As attribute importance is given in percentages in relation to each other, these add up to $100 \%$. The conjoint interviews revealed that the most important attribute by far is the supplied service itself, namely prevention of physical or mental illness, team building, or a combination thereof. This attribute consumes more than one quarter $(26 \%)$ of overall importance. The approach of providing the coaching/training is also of high relevance for the choices (16\%). The attributes contract, affiliation, and customization show almost identical importance weights between $11 \%$ and $12 \%$, while the factor "awarding" is of slightly lower importance (8\%). The fact whether the supplier is certified or not is of minor relevance for the respondents' choices (4\%). Also additional services, comprising navigation function, needs assessment and occupational integration management show only low relevance (3.5-4\%).

Next results we derived from ACBC are partial utility values for each single attribute level. As partial utilities are computed across all respondents, they reflect averages thus equalizing differences in preferences between respondents.

The following Figure 4 and Figure 5 show attribute levels and related partial utilities in an overview. For interpretation, it is important to note that utilities within an attribute are adjusted to zero. This means that, in sum, partial utilities of attribute levels add up to zero within the same attribute. Consequentially, negative values do not mean a negative utility. The other way round, also attribute levels with negative value have a utility i.e. are beneficial, though below average utility of the attribute. As utilities relate to single attributes only, a comparison of utilities across attributes is not useful. 
Figure 4. Attribute Levels and Partial Utilities for the Attributes Supplied Services, Approach, Contract, and Affiliation

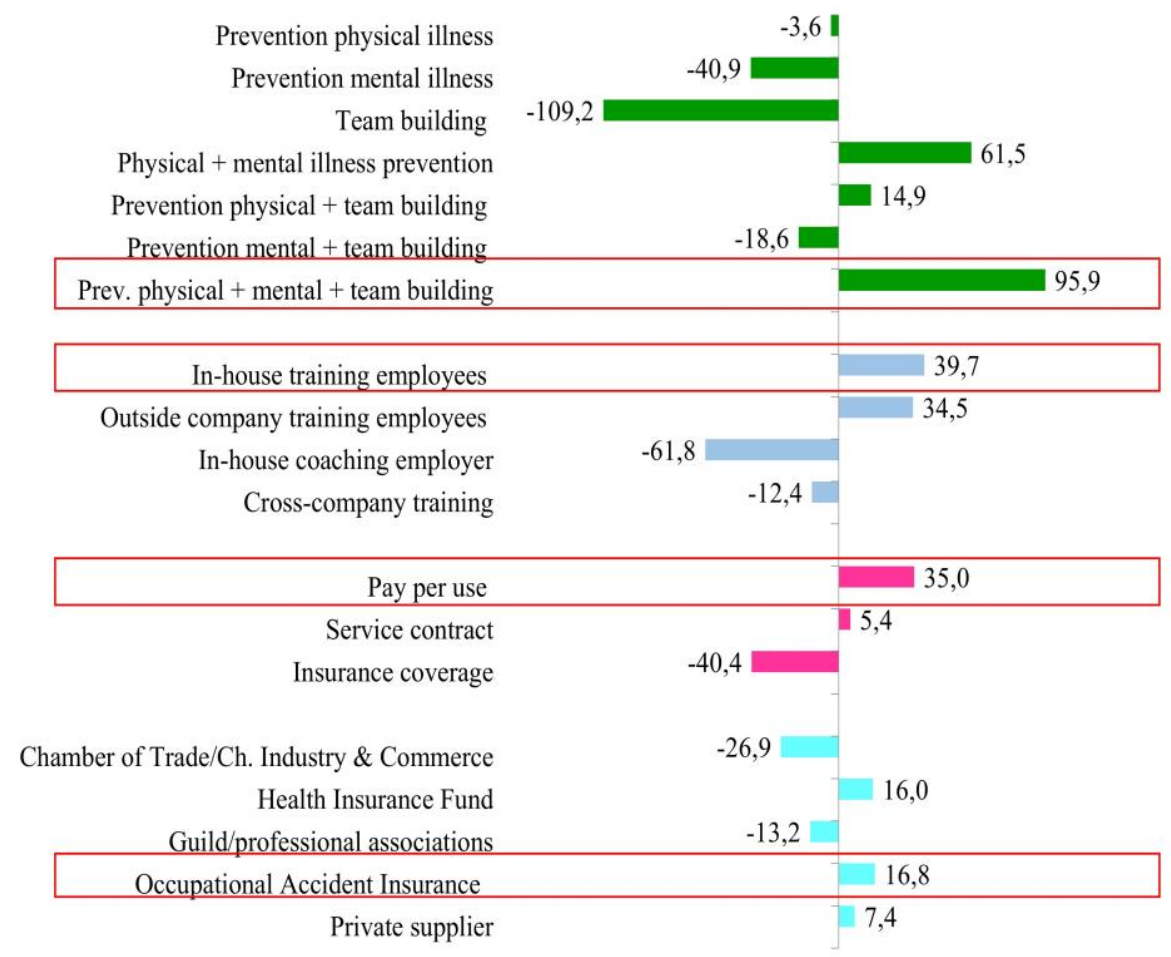

Figure 5. Attribute Levels and Partial Utilities for the Attributes Customization, Awarding, Supplier Certification, and Additional Services

\begin{tabular}{|c|c|c|}
\hline Customised to individual employees & & 29,0 \\
\hline Customised to individual company & & 31,8 \\
\hline Branch-specific tailoring & $-3,7$ & \\
\hline No customisation & $-57,1$ & \\
\hline No award & & 21,6 \\
\hline „Healthy Workplace“ award &,- 1 & \\
\hline TÜV-award & $-21,5$ & \\
\hline No supplier certification & $-7,9$ & \\
\hline Supplier certification & & 7,9 \\
\hline Additional service: needs assessment & & 11,6 \\
\hline No needs assessment & $-11,6$ & \\
\hline Additional service: navigation & & 6,0 \\
\hline No navigation function & $-6,0$ & \\
\hline Occupational integration management & & 10,9 \\
\hline No occ. integration management (BEM) & $-10,9$ & \\
\hline
\end{tabular}

In Figure 4 and Figure 5, all attribute levels with highest partial utility 
value are surrounded by a frame; the combination of these highlighted attribute levels delivers the service package generating the highest utility.

Not surprisingly, respondents prefer a complete service package, comprising the prevention of physical and mental illness as well as team building efforts. Stand-alone services are least attractive, in particular teambuilding as a stand-alone service shows very low utility. Trainings preferably should be provided to the employees, either in-house or outside the company. In-house coaching for employers and cross-company training, by contrast, show values below average. With respect to affiliation, health insurance funds and occupational accident insurers are particularly preferred. Private supply is also of interest, which in our case means that - for some respondents - the commercial supplier does not necessarily have to seek for cooperation. Affiliations to the chamber of trade or a guild show utility values below average. Further, our results indicate that respondents prefer customized services. Individualized services, tailored to the needs of the company are sufficient; service offers matching individual employees' preferences do not generate a higher benefit. Generalized prevention programs are not promising alternatives. While it is useful for the supplier himself to hold a certification, awarding of the participating SME is dispensable, especially if the award is as we fictitiously suggested - provided by the German Technical Inspection Association (TÜV). The supply of needs assessment, navigation function, and occupational integration management is beneficial, though low attribute importance needs to be taken into account. We have to emphasize again that choices are made without taking costs into consideration

When distinguishing between number of employees/company size (without graphic representation), utilities differ significantly within the attributes supplied services, approach, affiliation, and supplier certification. In the smallest category (up to 3 employees) the prevention of physical illnesses is particularly highly rated as a stand-alone service. Team building and the coaching of the employer/CEO are more interesting for large companies (20+) compared to smaller sized enterprises. Middle and larger sized companies prefer a supplier holding a certification. As company size and sector are correlated, some differences in utility values may be caused by sector differences and vice versa.

Significant differences can also be found in utilities depending on whether an employer has experienced major problems due to absences of employees or not (without graphical representation). Differences appear within the supplied services, the contract form, and with respect to preferences for additional services. Employers with few or no problems due to absences prefer services for physical illness prevention. The preference for physical illness prevention in combination with team building is significantly higher compared to employers with higher experience of problems. If experienced problems are considerable or high, employers tend to prefer mid- to long-term contracts or insurance contracts. Pay per use contracts are strongly preferred by SME with few problems due to absenteeism. Additional services, such as the navigation function and occupational integration management become increasingly useful 
the more problems employers experienced.

\section{Results regarding Willingness to Pay}

Coming now to the results of WTP interviews, we find that the vast majority of SME $(76 \%)$ is generally willing to pay for their individual ideal service package (see Figure 6). Almost $40 \%$ are willing to pay between 5 Euro and 10 Euro per month and employee. This result is quite surprising as our qualitative pre-studies indicated low or no WTP. An interpretation for this discrepancy might be that during interviews and focus group discussions the prevention programs were not specified but during the conjoint interview respondents built up an individual service bundle which exactly meets their requirements.

Figure 6. Willingness to Pay

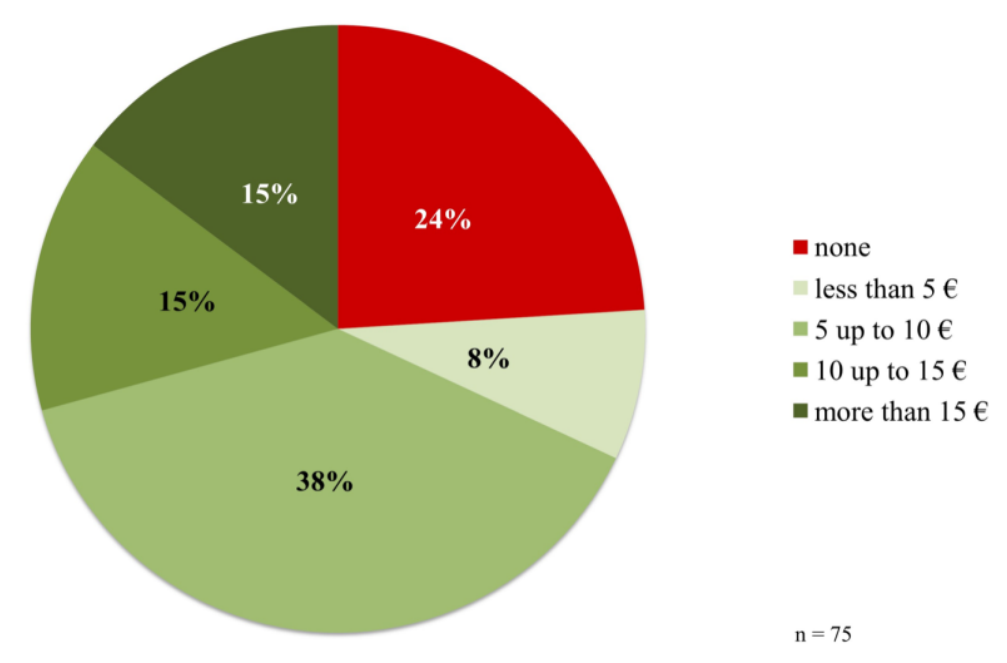

Within the group of those willing to pay for services, average WTP increases with company size as displayed in Figure 7. 
Figure 7. Willingness to Pay According to Company Size

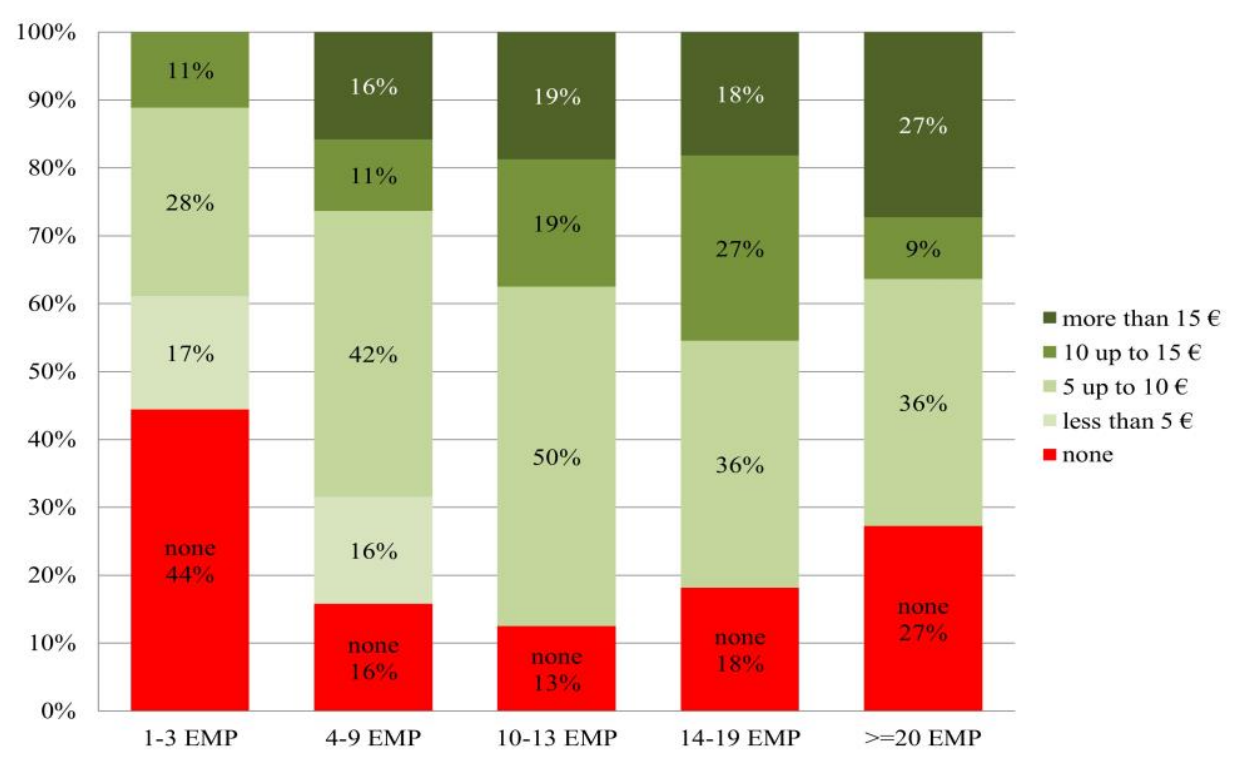

Finally, we also wanted to know whether there are differences in partial utilities of attribute levels between the group willing to pay or not, thus combining the results from ACBC with answers from WTP interviews. The differences are shown in the following Figure 8 and Figure 9.

Figure 8. Utilities by General Willingness to Pay for the Attributes Supplied Services, Approach, and Contract

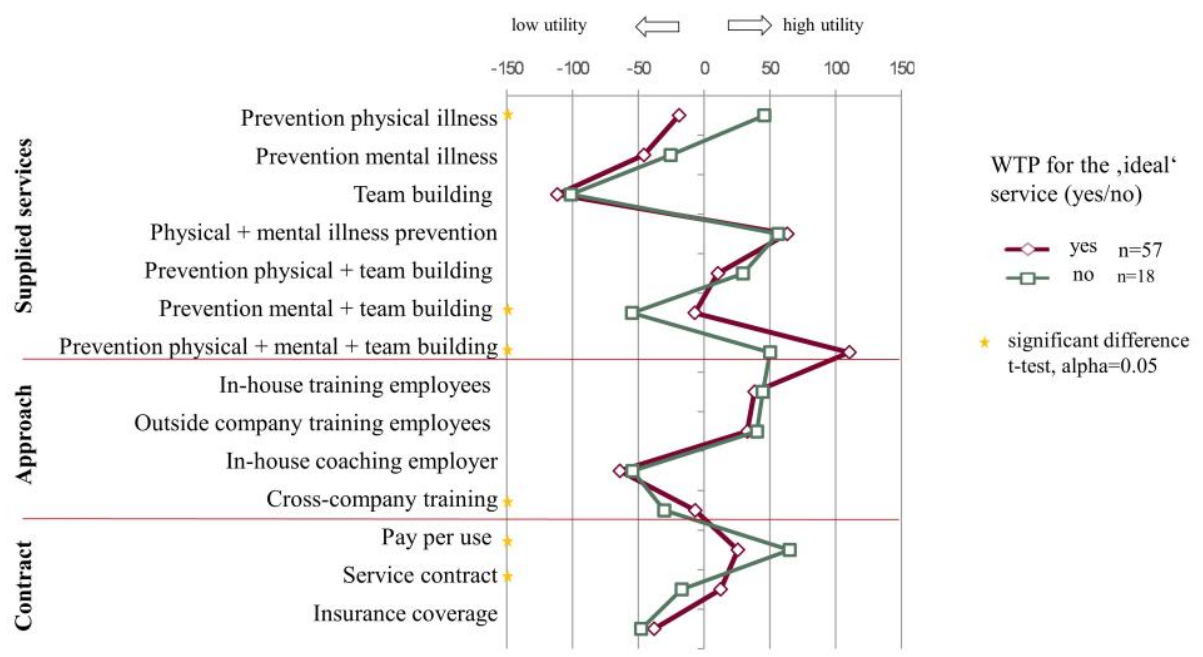


Figure 9. Utilities by General Willingness to Pay for the Attributes Affiliation, Customization, Awarding, Certification, and Addit. Services

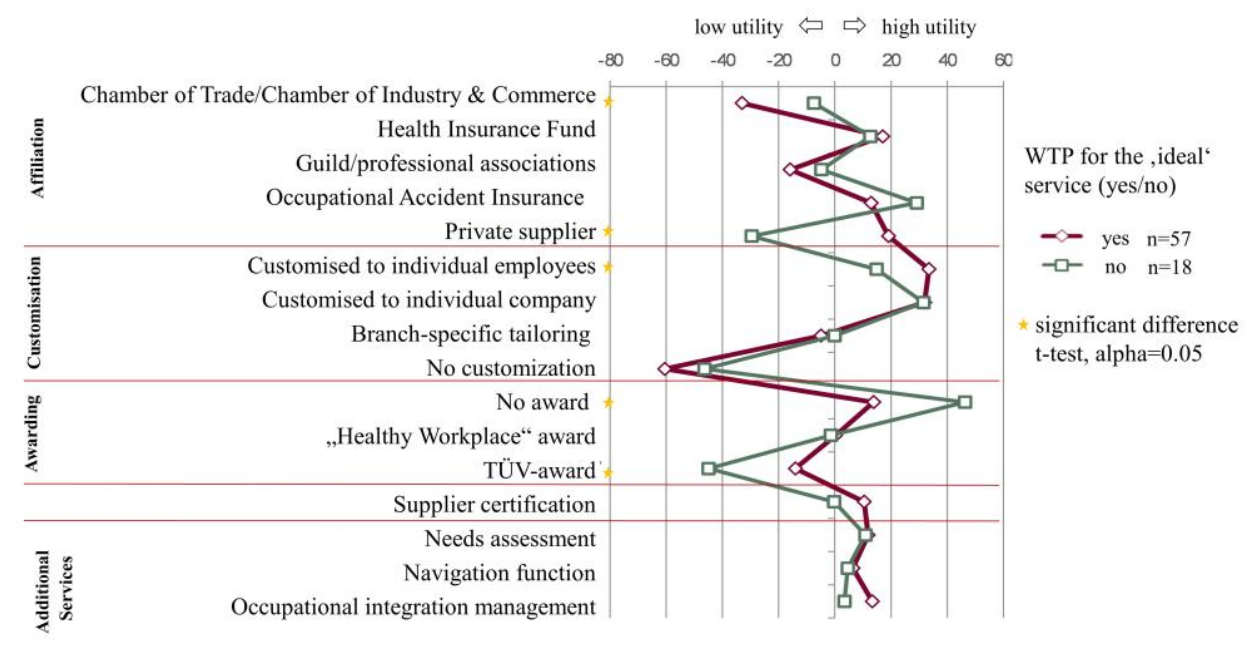

Large and in most cases significant differences in utility values exist between the groups willing and not willing to pay for services in all attribute categories. SME willing to pay find a combination of physical/mental illness prevention and team building particularly useful and the service offered should be rather customized to the individual employee compared to branch-specific or company-specific customization. An explanation for this finding may be that respondents not willing to pay suspect higher costs if trainings are customized to individual employees. The group willing to pay for services also prefers more strongly cross-company trainings over in-house trainings compared to the group not willing to pay. A mid- to long-term contract or an insurance-based contract is preferred over a contract based on payment per use. Private supply of services is particularly attractive for SME willing to pay for services. SME not willing to pay prefer stand-alone services, in particular the prevention of physical illnesses. For this group an affiliation with the Chamber of Trade/Chamber of Industry and Commerce is significantly more attractive compared to the group willing to pay. Services offered by a Chamber maybe assumed to be free of charge. For SME without willingness to pay, awarding is dispensable. Supposedly, the respondents anticipate hidden cost with the award.

\section{Discussion and Conlusions}

A major problem for SME and microenterprises in providing prevention and occupational rehabilitation to their employees is the lack of qualified support structures. SME prefer individualized programs, which also take into account individual workplace conditions. With respect to occupational rehabilitation, assistance is required in the coordination between multiple players involved in the (re)integration process. 
According to our results, a comprehensive service package tailored to the needs of the individual company should be offered on a pay per use basis. The most preferred affiliations for a private supplier are social insurance providers, either health insurance funds or occupational health insurers. As opposed to our previous results from qualitative pre-studies, we find that SME are indeed willing to pay for services. However, respondents revealed WTP only after we explained the service in detail and allowed for tailoring it according to their specific needs. As the service package is complex, it seems to be difficult for potential clients to value the service. A first recommendation to the private service unit, the "Healthy at Work" project supports, is therefore to accompany market introduction by a campaign, carefully explaining the facts and advantages. Our study further disclosed that private supply of services is particularly attractive for employers willing to pay. A possible interpretation for this finding is that private suppliers are supposed to provide high standard of service. We finally also experienced that WTP within the group of microenterprises is very low and that average WTP increases with company size. However, microenterprises are most in need to offer prevention and occupational health services to their employees as they are especially vulnerable to problems due to absences. It is therefore of particular importance to offer appealing and affordable occupational health services to this group. For this purpose cooperation would be a useful strategy for a private service provider, most advisably with a social insurance provider.

Limitations of the study clearly emerge due to the complexity of the subject, although we took account of this aspect by taking several countermeasures, i.e. by selecting an adaptive form of $\mathrm{CA}$, by personal interviewing, and finally also by separating WTP questions from conjoint interview. Also, we cannot exclude sequence effects due to the fixed order in the attribute list. Consequentially, high utility may be assigned to the attributes listed on the top of the questionnaire and lower values to the attributes at the bottom. Finally, WTP estimations have to be interpreted with caution as refer to the ideal service package of the individual respondent.

\section{References}

BAuA [=Bundesanstalt für Arbeitsschutz und Arbeitsmedizin] 2012. Volkswirtschaftliche Kosten durch Arbeitsunfähigkeit 2012. Online available: www.baua.de (10.07.2014)

Bourque, L. B. and Fielder, E. P. 2003. How to Conduct Self-Administered and Mail Surveys. Thousand Oaks CA. Sage Publications. 2nd Edition.

Bridges, J. F.P., Brett Hauber, A., Marshall, D., Lloyd, A., Prosser, L.A., Regier, D. A., Reed J. F., and Mauskopf, J. 2011. Conjoint Analysis Applications in Health-a Checklist: A Report of the ISPOR Good Research Practices for Conjoint Analysis Task Force. In Value in Health 14 (2011), 403-413.

Cacace, M., Franz, I., Braun-Beustrin, D., and Ratz, D. 2015. Small and medium-sized enterprises' preferences for occupational health services and willingness to pay. In Healthy at Work - Interdisciplinary perspectives, Wiencke, M., Fischer, S., Cacace, M. Ed. Springer forthcoming 2015. 
Chrzan, K. 1994. Three Kinds of Order Effects in Choice-based Conjoint Anlaysis. In Marketing Letters 5,2 (1994), 165-172.

Clark, M. D., Determann, D., Petrou, St., Moro, D., and De Bekker-Grob, E. W. 2014. Discrete Choice Experiments in Health Economics: A Review of the Literature. In Pharmacoeconomics 32, 9 (2014), 883-902.

Cunningham, C. E., Deal, K., and Chen, Y. 2010. Adaptive Choice-Based Conjoint Analysis - A New Patient-Centered Approach to the Assessment of Health Service Preferences. Patient 3,4 (2010), 257-273.

De Bekker-Grob, E. W., Ryan M., and Gerard, K. 2012. Discrete Choice Experiments in Health Economics: A review of the Literature. In Health Economics 21, 145172.

Fuchs, J., Soehnlein, D., and Weber, B. 2011. Projektion des Arbeitskräfteangebots bis 2050; Rückgang und Alterung sind nicht mehr aufzuhalten. IAB-Kurzbericht Nr.16 (Aug. 2011), Institut für Arbeitsmarkt- und Berufsforschung (IAB) der Bundesagentur für Arbeit.

Green, P. E. and Srinivasan, V. 1978. Conjoint Analysis in Consumer Research: Issues and Outlook. J. of Consumer Research 5,2 (1978), 103-123.

Harrison, J., Woods, A., and Dickson, K. 2013. Occupational health purchasing behaviour by SMEs--a new theoretical model. Occupational Medicine 63,7 (2013), 510-512.

Johnson, R. 2008. A Perspective on Adaptive CBC (What Can We Expect from Respondents?) Sawtooth Software, Research Paper Series. Online available: http://www.sawtoothsoftware.com/ (24.10.2014).

Krosnick, J. A., Holbrook, A. L., Berent, M. K., Carson, R. T., Hanemann, W. M., Kopp, R. J., Mitchell, R. C., Presser, S., Ruud, P. A., Smith, V. K., Moody, W. R., Green, M. C., and Conaway, M. 2002.The impact of 'no opinion' response options on data quality: Non-attitude reduction or an invitation to satisfice? Public Opinion Quarterly, 66 (2002) 371-403.

Lancsar, E. and Louviere, J. 2006. Deleting 'irrational' responses from discrete choice experiments: a case of investigating or imposing preferences? Health Economics 15,8 (2006), 797-811

Luce, R.D. and Tukey, J.W. 1964. Simultaneous conjoint measurement: a new scale type of fundamental measurement". In Journal of Mathematical Psychology 1, 1, $1-27$.

Miller, P., Rossiter, P., and Nuttall, D. 2002. Demonstrating the economic value of occupational health services.In Occupational Medicine 52,8 (2002), 477-483.

Orme, B. 2013. Which Conjoint Method Should I Use? Sawtooth Software, Research Paper Series. Online available: http://www.sawtoothsoftware.com/ (24.10.2014).

Orme, B. 2002. Formulating Attributes and Levels in Conjoint Analysis. Sawtooth Software, Research Paper Series. Online available: http://www.sawtoothsoftware .com/ (24.10.2014).

Rao, V.R. 2014. Applied Conjoint Analysis. Springer (2014).

Ratcliffe, J. 2000. The use of conjoint analysis to elicit willingness to pay. Proceed with caution? International Journal of Technology Assessment in Health Care 16,1 (2000), 270-290.

Ryan, M. and Gerard, K. 2003. Using discrete choice experiments to value health care programmes: current practice and future research reflections. In Applied Health Economics and Health Policy 2,1 (2003), 55-64.

Ryan, M. and Farrar S. 2000. Using conjoint analysis to elicit preferences for health care. BMJ 320 (2000), 1530-1533.

Ryan, M., Scott, D. A., and Donaldson, C. 2004. Valuing health care using willingness 
to pay: a comparison of the payment card and dichotomous choice methods. In Journal of Health Economics 23,2 (March 2004),

237-258.

Sawtooth Software 2014. ACBC Technical Paper. Online available: http://www. sawtoothsoftware.com/ (24.10.2014).

Zelfel R.C., Alles T., and Weber A. 2011. Gesundheitsmanagement in kleinen und mittleren Unternehmen - Ergebnisse einer repräsentativen Unternehmens befragung. In Das Gesundheitswesen 73 (2011),515-519. 